\title{
Design of Greenhouses with High Light Transmittance: An Implementation in Two Different Conditions
}

\author{
Kivanc Topcuoglu ${ }^{1,}$, , Halil Baki Unal ${ }^{2}$ \\ ${ }^{1}$ Department of Construction, Mugla Vocational School Mugla Sitki Kocman University, Mugla, Turkey \\ ${ }^{2}$ Department of Agricultural Structures and Irrigation, Faculty of Agriculture, Ege University, Izmir, Turkey
}

Email address:

ktopcuoglu@mu.edu.tr (K. Topcuoglu)

*Corresponding author

\section{To cite this article:}

Kivanc Topcuoglu, Halil Baki Unal. Design of Greenhouses with High Light Transmittance: An Implementation in Two Different Conditions. American Journal of Agriculture and Forestry. Vol. 7, No. 4, 2019, pp. 152-161. doi: 10.11648/j.ajaf.20190704.15

Received: July 3, 2019; Accepted: August 5, 2019; Published: August 20, 2019

\begin{abstract}
In periods when greenhouses need heating, heating costs can be reduced if the interior of the greenhouse receives a greater amount of sunlight. For this, the greenhouse surface slope angles need to be increase in such a way that the rays of the sun fall perpendicular to the greenhouse surface in the winter months when they are at a lower angle to the surface of the Earth. In this study, an investigation was made of greenhouse surface geometry which would allow a high level of sunlight penetration in winter conditions in the provinces of Antalya and Muğla, where greenhouse agriculture is widely practiced. The Venlo type glass greenhouse with vertical side surfaces, which is extensively used in the study area, was taken as a reference. Two different models of glass greenhouse were designed with a geometry which would increase the light penetrability of the side wall surfaces, taking account of the global radiation and the hours of sunlight for a six-month period (October to March) in each of the provinces. The geometry of the model greenhouses and the reference greenhouses was compared in terms of mean penetrability to sunlight and the energy values of the sunlight passing through. It was determined that the sunlight penetrability values of the model greenhouses were $7.86 \%$ higher than those of the reference greenhouse in Antalya province and $7.36 \%$ higher in Muğla province. These results show that the geometry of both model greenhouses was able to benefit at a higher level from the sun's rays than fixed surface greenhouses. Greenhouses constructed according to the planned geometry will help to reduce the winter heating costs of greenhouse agriculture in mild climates similar to the study area, and help to enable greenhouse production in cooler climates. It is thought that in this way, greenhouse crop production will be possible over a wider area and throughout a longer period of the year.
\end{abstract}

Keywords: Greenhouse Surface, Winter Cultivation, Solar Energy, Solar Light Transmittance

\section{Introduction}

Today in Turkey, approximately 23.9 million ha of land is used for agriculture [16]. That is, agriculture is practiced on $31.1 \%$ of the country's land area, which works out at approximately $3 \mathrm{da}$ of agricultural land per person. According to this, Turkey is fourteenth in the world in terms of the total area of agricultural land, and 40th in terms of agricultural land per person [3]. For this reason, efficiency and productivity in agriculture are of great importance for the country. Among the steps which should be taken in the direction of improving the quality and quantity of agricultural production is under-cover cultivation in greenhouses.
Greenhouse production in Turkey is conducted mainly in the Mediterranean and South Aegean regions, where the climate is warm. The total area of under-cover cultivation in the country has reached 75217 ha, of which approximately 44087 ha consists of glass and plastic greenhouses, and 31130 ha is low or high tunnels [16]. Tunnels are generally used only to ensure early production, while greenhouses are used in order to carry on crop production over a longer period of time by controlling environmental conditions. The use of greenhouses is also spreading quickly because it enables higher yields per unit of land. Tunnel systems are used over the greatest area in the Çukurova region for growing field crops at the seedling stage, while in other regions, greenhouses have 
begun to take the place of tunnels.

The problems of low temperature and high humidity in greenhouses are solved with heating [17]. In Turkey, greenhouse heating is only used to protect the plants from frost, so that solar radiation is the most important way of heating greenhouses. Of the energy coming from the sun, $25-35 \%$ is taken by the surface of the greenhouse, and $10 \%$ by the construction material. The $55-65 \%$ which remains passes into the greenhouse, but a further $10 \%$ is lost by reflection. In this way, $40-50 \%$ of the total heat energy coming from the sun is actually used in the greenhouse [22]. In a study by Emekli and Büyüktaş [8] examining the characteristics of greenhouse covering materials, it was reported that light transmittance was 71$95 \%$ depending on the type of glass, and that polyethylene greenhouse covers was the product with the nearest light transmittance to glass, at $85-96 \%$ on first use. Kincay [13] stated that radiation arriving at a light-transmitting surface suffers transmission losses in the form of reflection and absorption.

The amount of radiation energy entering the greenhouse depends on the latitude of the location of the greenhouse as well as the cloudiness of the area, air pollution, the light absorption of the greenhouse covering, the amount of dirt on the covering, and the angle of the greenhouse roof [19].

Olgun [14] states that greenhouses with gable roofs brought together so that the roof forms an M shape are called Venlo type greenhouses, and that the width of each section is $3.20 \mathrm{~m}$. Venlo type greenhouses are very widely used today. For example, approximately $85-90 \%$ of newly built greenhouses in the Netherlands are Venlo type greenhouses [18]. More than $80 \%$ of greenhouses in Germany are glass greenhouses. Because the cost of glass greenhouses with wide sections is rather high, growers in Germany have for the past ten years preferred Venlo type greenhouses among the types of glass greenhouse [7].

In a study of the structural and functional characteristics of greenhouses in the countries of the European Union, Elsner et al. [7] stated that the greatest light transmittance was given by a greenhouse aligned east to west with an asymmetric roof angle of $25^{\circ}-65^{\circ}$. In another study, it was stated that in greenhouses with a $25^{\circ}$ roof angle and symmetric construction, light transmittance was greater in an east-west alignment, but that in a greenhouse of the same type in the summer months, light transmittance was greater in a northsouth alignment [7].

Venlo type greenhouses are glass greenhouses of light construction, with a roof surface of length $3.20 \mathrm{~m}, 6.40 \mathrm{~m}$ or $9.60 \mathrm{~m}$. The height of the side walls of this type of greenhouse can be between $2.40 \mathrm{~m}$ and $2.80 \mathrm{~m}$. The columns and guttering systems are integrated. Optimum sections are used in the roof trussing and between the supporting columns, providing the slope. In Venlo type greenhouses, ventilation is provided not in the walls but in the roof. In ventilation systems, movement is provided from the gutters, enabling vents to open upwards or downwards, so that large ventilation openings are obtained, and the window, turning on a hinge, provides the maximum ventilation when open [15]. Olgun [14], stated that the width of each block of Venlo greenhouses was $3.20 \mathrm{~m}$.

Çakır and Şahin [5] stated that the for solar energy gaining elliptic type is the optimum one in all analyzed types of greenhouses for Bayburt conditions for all floor areas. It is followed by uneven-span, even-span, semi-circular and vinery type of greenhouses respectively.

In order to be able to make the calculations of refraction and reflection relating to determining the net amounts of radiation entering the greenhouse, it is necessary to know the angles at which the direct and distributed components of radiation strike the greenhouse surfaces. When researching the geometry of a surface so that it will benefit the most from the heat of the sun, the construction of the surface considered must be simple [20].

In a study conducted in Egypt at $30.36^{\circ} \mathrm{N}, 31.22^{\circ} \mathrm{E}$ and an altitude of $15 \mathrm{~m}$, Ali [2] examined the hourly amount of radiation entering a greenhouse. In this study, it was found that in the middle of the day when the hour angle was $0^{\circ}$, the angle made with the normal of a vertical surface was $51.28^{\circ}$, and at the beginning of the day, when the hour angle was $60^{\circ}$, the angle made with the normal of a vertical surface was $77.14^{\circ}$.

With the newly developed greenhouse coating materials, the results obtained with greenhouse geometry can be improved. Hemming et al. [9] stated that the application of flexible thin glass in greenhouses can reduce energy need up to $\% 20$.

The aim of this study was to plan the geometry of a greenhouse which could take in the largest possible amount of heat from the sun in the cold winter months in the provinces of Antalya and Muğla. For this purpose, a model greenhouse surface was first planned mathematically, in a way that would increase the solar radiation entering the greenhouse. Later, this model was compared with the greenhouse surface with regard to light transmittance of the model greenhouse surface.

\section{Materials and Methods}

\subsection{Climate Data of the Study Area}

The material used in the study consisted of the mean long-term daily values of global radiation $\left(\mathrm{kWh} \mathrm{m}^{-2} \mathrm{day}^{-1}\right)$ and hours of sunshine (h) which were needed for heating in six periods (October, November, December, January, February and March) in the climatic conditions of Antalya and Muğla provinces. This data was obtained from the General Directorate of Renewable Energy (YEGM) (see Table 1). 
Table 1. Global radiation values and hours of sunshine for Antalya and Muğla provinces (YEGM, 2018).

\begin{tabular}{|c|c|c|c|c|}
\hline \multirow[b]{2}{*}{ Months } & \multicolumn{2}{|l|}{ Antalya } & \multicolumn{2}{|l|}{ Muğla } \\
\hline & $\begin{array}{l}\text { Global Radiation Values } \\
\left(\mathrm{I}_{\mathrm{y}}\right),\left(\mathrm{kWh} \mathrm{m}^{-2} \mathrm{day}^{-1}\right)\end{array}$ & $\begin{array}{l}\text { Daily Mean Hours of Sunshine } \\
\left(t_{g}\right),(h)\end{array}$ & $\begin{array}{l}\text { Global Radiation Values } \\
\left(I_{\mathrm{y}}\right),\left(\mathrm{kWh} \mathrm{m}^{-2} \mathrm{day}^{-1}\right)\end{array}$ & $\begin{array}{l}\text { Daily Mean Hours of } \\
\text { Sunshine }\left(\mathrm{t}_{\mathrm{g}}\right),(\mathrm{h})\end{array}$ \\
\hline October & 3.93 & 7.68 & 3.96 & 7.85 \\
\hline November & 2.51 & 5.97 & 2.56 & 6.01 \\
\hline December & 1.92 & 4.55 & 1.88 & 4.67 \\
\hline January & 2.12 & 4.95 & 2.11 & 5.13 \\
\hline February & 2.57 & 6.10 & 2.42 & 6.20 \\
\hline
\end{tabular}

\subsection{Description of Reference Greenhouse}

The vertical sided, glass covered, triple block Venlo type greenhouses which are widely preferred in the study area were chosen as greenhouse reference construction. The reference greenhouse had a side height of $260 \mathrm{~cm}$, a roof angle of $25^{\circ}$, a roof height of $74 \mathrm{~cm}$ and a roof ridge height of $334 \mathrm{~cm}$, and the width of each block was $320 \mathrm{~cm}$. The total south-facing area per unit of height $(\Sigma A)$ in the projected cross-section of the reference greenhouse was 7.85 m2 (see Figure 1, Table 2).

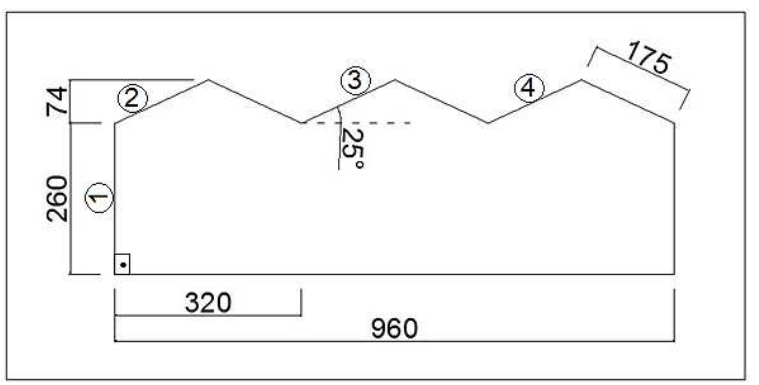

Figure 1. Cross-section and dimensions of reference greenhouse.

Table 2. Surface geometry of the reference greenhouse.

\begin{tabular}{llll}
\hline Reference green- house surface No & Slope $\left(^{(}\right)$ & Length $(\mathbf{c m})$ & Surface area per $\mathbf{1}$ m height $\left(\mathbf{m}^{2}\right)$ \\
\hline 1 & 90 & 260 & 2.60 \\
2 & 25 & 175 & 1.75 \\
3 & 25 & 175 & 1.75 \\
4 & 25 & 175 & 1.75 \\
$\Sigma$ A & & & 7.85 \\
\hline
\end{tabular}

In both the reference and the model greenhouses, the long axis was planned on an east-west alignment and the sloping surfaces faced the sun, in order to gain maximum advantage from solar radiation.

\subsection{Calculation of the Amount of Solar Radiation Passing Through the Greenhouse Surfaces}

The steps followed and the equations used in calculating the amount of solar radiation passing through the greenhouse surfaces are given below [21].

In order to be able to determine the solar radiation passing through the greenhouse surfaces, it is first necessary to know the intensity and incidence angle of the radiation arriving at the surface and the coefficient of its transmittance through the surface.
At any time when the sun is shining, the total momentary radiation striking a sloping surface on the Earth is expressed as (It) $\left(\mathrm{Wh} \mathrm{m}^{-2}\right)$, the momentary direct radiation as (Ide), the momentary distributed radiation as (Iye), and the total momentary reflected radiation as (Iya) (see Eq. 1).

$$
I_{t}=I_{d e}+I_{y e}+I_{y a}
$$

Momentary direct radiation $\left(I_{d e}\right)\left(\mathrm{Wh} \mathrm{m}^{-2}\right)$ is calculated by multiplying the direct radiation conversion factor $\left(R_{d}\right)$ by the momentary radiation $\left(I_{d s}\right)\left(\mathrm{Wh} \mathrm{m}^{-2}\right)$ (see Eq. 2).

$$
I_{d e}=R_{d} \cdot I_{d s}
$$

$R_{d}$ is calculated for vertical surfaces with the help of Eq.3.

$$
R_{d}=\frac{\cos (d) \sin (e) \cos (\gamma) \cos (w)+\cos (d) \sin (\gamma) \sin (w)-\sin (d) \cos (e) \cos (\gamma)}{\cos (e) \cos (d) \cos (w)+\sin (d) \sin (e)}
$$

where $d$ is the declination angle, $e$ is the latitude angle and $\gamma$ is the surface azimuth angle; when the projection on a horizontal plane of the normal of an inclined plane is taken, it is the angle between them, which shows the south. The value of this angle is negative from south to east and positive from south to west; for the side wall on the south it is zero, and for a side wall on the west it is $90^{\circ}$. The value of $w$ is calculated as the hour angle and $w=(t-12)$, where $t$ represents the time.

Momentary radiation striking a horizontal plane $\left(I_{d s}\right)$
$\left(\mathrm{Wh} \mathrm{m}^{-2}\right)$ is calculated in the following way.

$$
I_{d s}=I_{t s}-I_{y s}
$$

where $I_{t s}$ is the total momentary radiation $\left(\mathrm{Wh} \mathrm{m}^{-2}\right)$ striking a horizontal plane calculated by Eqs. (5) - (8), and $I_{y s}$ is the momentary distributed radiation $\left(\mathrm{Wh} \mathrm{m}^{-2}\right)$ calculated by Eq. (9).

$$
I_{t s}=\cos \left[\frac{\pi}{\operatorname{tg} i}(t-12)\right]
$$


where $t$ is time, is function amplitude and $t_{g i}$ is the length of an imaginary day. These are calculated by the following equations.

$$
\begin{gathered}
\mathrm{A}_{\mathrm{ts}}=\frac{\pi I_{y s}}{2 t_{g i}} \\
t_{g i}=1.25 \mathrm{tg}^{0.875}
\end{gathered}
$$

where $t_{g}$ is day length, calculated as below.

$$
\begin{gathered}
t_{g}=\frac{2}{15} \operatorname{Arccos}[-\tan (e) \tan (d)] \\
I_{y s}=A_{y s} \cos \left[\frac{\pi}{t g}(t-12)\right]
\end{gathered}
$$

where $A_{y s}$ is function amplitude, calculated as below.

$$
\mathrm{A}_{\mathrm{ys}}=\frac{\pi I_{y}}{2 t_{g}}
$$

where Iy represents the total radiation values $\left(\mathrm{Wh} \mathrm{m}^{-2}\right)$ striking a horizontal plane, calculated using daily global radiation values measured of the General Directorate of Renewable Energy (YEGM, 2018) in both provinces in the research area.

The momentary distributed radiation in Eq. 1 (Iye) $\left(\mathrm{Wh} \mathrm{m}^{-2}\right)$ is calculated by multiplying the distributed radiation conversion factor (Ry) by the momentary radiation (Iys).

$$
\tau_{d}=0.88-7.3910^{-3} \theta+3.4810^{-4} \theta^{2}-4.13710^{-6} \theta^{3}
$$

The incidence angle of radiation on to the glass surface varies throughout the hours of sunshine. For this reason, it is necessary to calculate the angle of incidence to the surface for each hour when there was sunshine in the five-month period examined.

In determining incident angles, use was made of various specific angles between solar radiation and surfaces on the Earth $(\alpha, \beta, \gamma, \theta, \theta z, \Phi, w, S) . \alpha$ (the angle of elevation) is the angle between the solar radiation $(H n)$ and a horizontal surface. $\beta$ (the solar azimuth angle) is the angle showing the clockwise deviation of the solar radiation relative to the north. $\gamma$ (the surface azimuth angle) is the angle which shows the deviation of the perpendicular of a surface making an angle with the plane of the ground relative to local longitude. $\theta$ (the incidence angle) is the angle between the perpendicular of an inclined surface and the solar radiation. $\theta z$ (the zenith angle) is the angle formed between the normal of a horizontal surface and the solar radiation. $\Phi$ (the latitude angle) is the angle between the plane of the equator and a

$$
I_{y e}=R_{y} \cdot I_{y s}
$$

where Ry is the distributed radiation conversion factor, calculated for vertical surfaces as below.

$$
R_{y}=\frac{1+\cos (\alpha)}{2}
$$

where $\alpha$ is the slope angle of the surface, recommended as Ry $=0.5$ for vertical surfaces [22].

Momentary reflected radiation (Iya) $\left(\mathrm{Wh} \mathrm{m}^{-2}\right.$ ) in Eq. 1 is calculated by Eq. 13 .

$$
I_{y a}=I_{t s} \rho \frac{1-\cos (\alpha)}{2}
$$

where $\rho$ is the ambient reflection rate, taken as having a mean value of 0.2 [22].

The amount of solar radiation passing through a glass surface $(\mathrm{Ig})\left(\mathrm{Wh} \mathrm{m}^{-2}\right)$ was calculated using Eq. 14.

$$
I_{g}=\tau_{d} I_{d e}+0.79\left(I_{y e}+I_{y a}\right)
$$

For single glass surfaces, the surface transmittance coefficient $\left(\tau_{d}\right)$ in direct radiation with radiation incidence angle $\theta$ was calculated as follows.

radial line to the center of the Earth. $W$ (the time angle) is the angular measurement of time, and is taken as equal to $15^{\circ}$ per hour. $S$ (the surface slope angle) is the angle a horizontal surface and an inclined surface [12]. Fig. 2 shows schematically the trigonometric statements concerning the angles between the sun and an inclined plane or surface.

The angle between the direction of the sun and the plane of the equator is known as the declination angle $(\delta)$. This angle varies between -3.45 and $23.45^{\circ}$, taking north as positive [4], and was calculated for the projected conditions in this study with the help of the following equation [6].

$$
\delta=23.45 \sin \left[\frac{360(284+n)}{365}\right]
$$

where $\mathrm{n}$ is the day of the year counting from 1 January, with which angle $\delta$ is to be calculated.

The angle of incidence of direct solar radiation $(\theta)$ is expressed with the following equation [11].

$$
\begin{gathered}
\cos \theta=\sin \delta \sin \Phi \cos S-\sin \delta \cos \Phi \sin S \cos \gamma+ \\
\text { uation (Kaynaklı et al. ,2012). } 155 \cos \delta \cos \Phi \cos S \cos w \text { and Forestry } 155+\cos \delta \sin \Phi \sin S \cos w+\cos \delta \sin S \sin \gamma \sin w
\end{gathered}
$$

As a result of the positioning of the greenhouse with its long direction aligned east-west, that is so that its long aspect was facing south, its surface azimuth angle $(\gamma)$ and its mean time angle $(w)$ had to be $0^{\circ}$. In this condition, the incidence angle of the solar radiation $(\theta)$ was calculated with the help of the following formula.

$$
\cos \theta=\sin \delta \sin \Phi \cos S-\sin \delta \cos \Phi \sin S+\cos \delta \cos \Phi \cos S+\cos \delta \sin \Phi \sin S
$$

When the incidence angle of solar radiation $(\theta)$ in relation

to an inclined surface is zero, the solar radiation will strike 
the surface perpendicularly, and the highest transmission coefficient will be obtained. Eq. 19 was obtained by revising Eq. 18 in accordance with the inclination angle of a surface which faces the solar radiation perpendicularly.

$$
1=\cos S \cos (\delta-\Phi)+\sin S \sin (\delta-\Phi)
$$

This equation expresses the relation between the declination angle $(\delta)$, the latitude angle $(\Phi)$ and the inclined surface that is the angle which the inclined surface of the greenhouse makes with the horizontal axis $(S)$.

\subsection{Design of the Model Greenhouse}

The angle made each month by six rectilinear surface parts of the long side surfaces of model greenhouses for Antalya and Muğla conditions were calculated with the help of Eq. 19 , and the ratio of surface lengths to total surface was calculated in inverse proportion to monthly global radiation values. In this way, the total amount of sunlight entering the model greenhouse in the six-month period from October to March was provided at the highest level. To this purpose, when creating the geometry of the side surface of the model greenhouse, calculations were made for each month of the surface inclination which the sun would strike perpendicularly, and of how much of the total greenhouse surface this surface would be. When calculating the ratio of the surface area for each month to the total surface area, the monthly global radiation values and the hours of sunshine obtained from the General Directorate of Renewable Energy were used (see Table 1).

The weighting coefficient of the plane of the side surface of the greenhouse for any month was calculated according to the ratio of the total global radiation value for that month $\left(I_{i}\right)$ to the six-month total global radiation value $\left(I_{\text {sum }}\right)$ (see Eqs. 20 and 21). The ratio of the weighting coefficient calculated for each month to the total of the weighting coefficients calculated for all months gives the ratio of the planes for each month in the length of the total side surface $\left(k_{i}\right)$ (see Eq. 22). It was intended that the surface areas of the model greenhouse and the reference greenhouse which faced south should be the same. In the model greenhouse, the surface area for any month $\left(A_{\text {model }}(i)\right.$ is calculated by multiplying the coefficient calculated for that month $\left(k_{j}\right)$ by the surface area of the reference greenhouse ( $\left.A_{\text {reference }}\right)$ (see Eq. 23).

$$
\begin{gathered}
I_{\text {sum }}=\sum_{i=\text { october }}^{\text {march }} I_{i} \\
a k_{i}=\frac{I_{i}}{I_{\text {sum }}} \\
k_{i}=a k_{i} / \sum_{i=\text { october }}^{\text {march }} a k_{i} \\
A_{\text {model }(i)}=k_{i} A_{\text {reference }}
\end{gathered}
$$

In this study, the most suitable surface geometry was researched by comparing the net solar energy gains of two model greenhouses developed for Antalya and Muğla provinces with a reference model greenhouse. For this, it is necessary first to determine the light transmittance coefficients $(T)$ which express the transmittance of total solar energy in the greenhouses for the glass material projected for the model greenhouses. The value of $T$ varies between 0 and 1. Figure 3 shows the values of $T$ relating to the angle $(\theta)$ of the light striking the side surfaces of the model greenhouses and the normal of the surface.

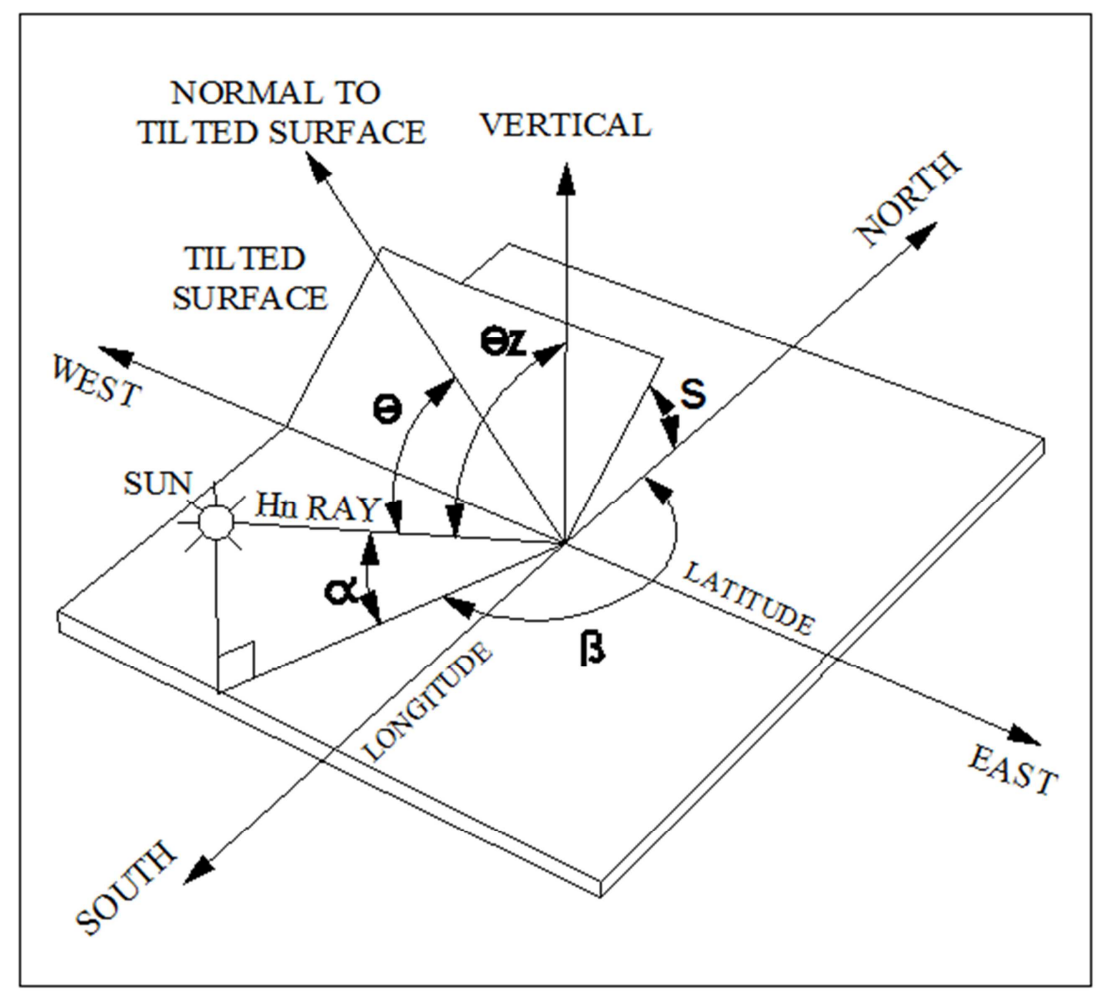

Figure 2. Angles between the Sun and a Surface (Kincay, 2013a). 


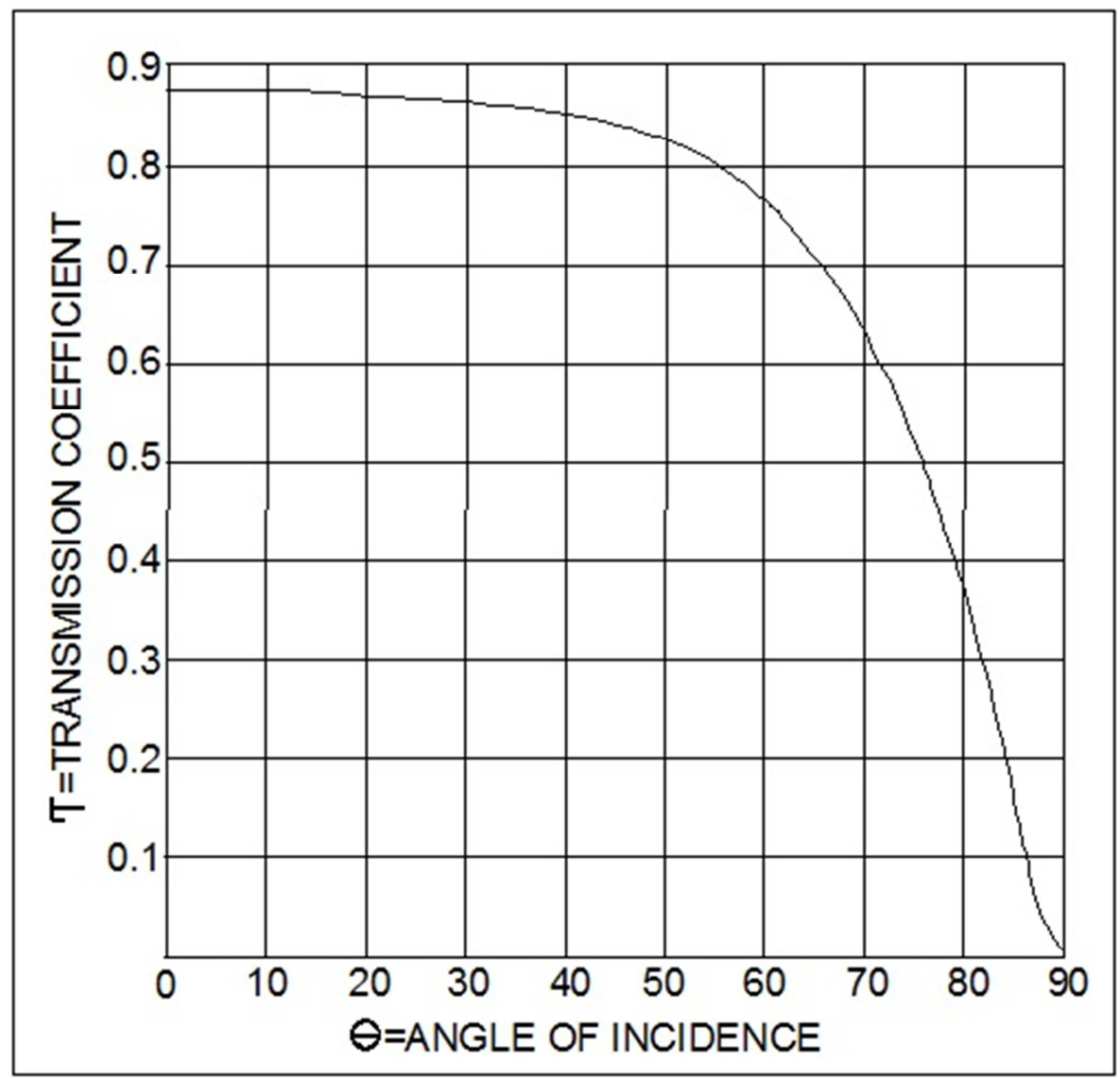

Figure 3. Nomogram of light passage coefficents of a glass surface [13].

The reference and model greenhouses were compared according to the total net global radiation gains passing through unit lengths of the south-facing greenhouse surfaces.
Figure 4 shows the greenhouse surfaces taken into account in the calculations.

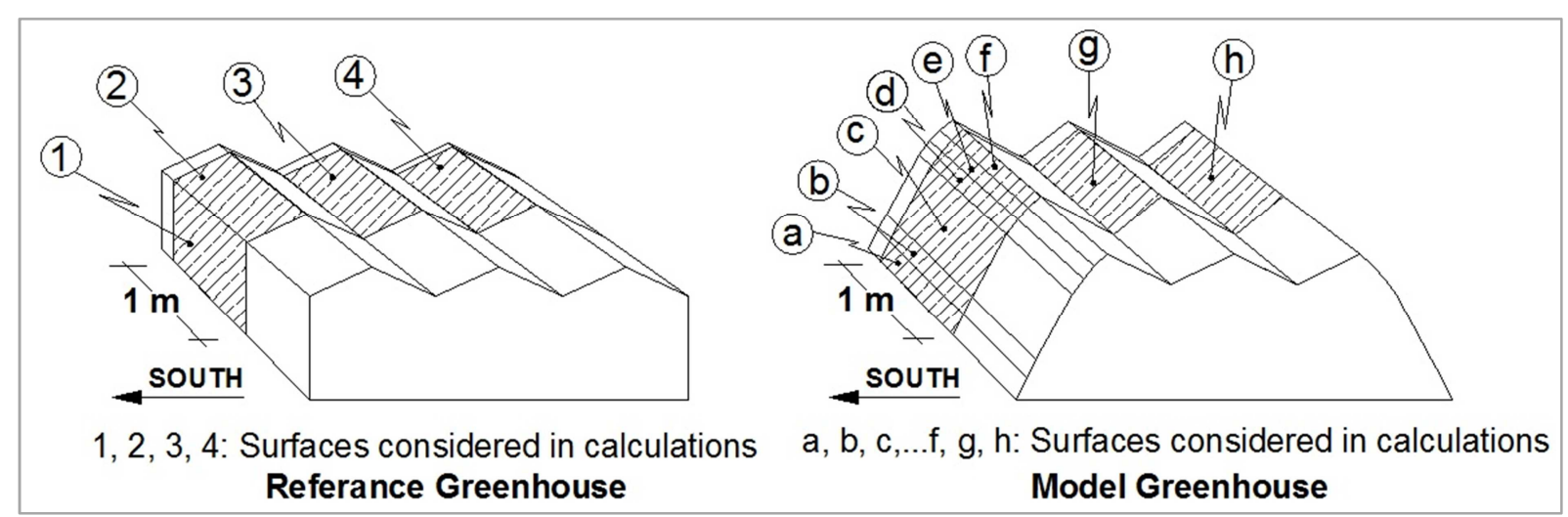

Figure 4. Greenhouse surfaces taken into account in calculating global radiation gain in reference and model greenhouses.

The total net global radiation gain of a greenhouse $\left(Q_{\text {sum net }}\right)$ $(\mathrm{kWh})$ is calculated with the help of Eq. 24 using the separately calculated $T$ coefficients for the areas with different inclinations which form the side surface of the greenhouse, the global radiation values coming to these areas $\left(Q_{\text {incoming }}\right)\left(\mathrm{kWhm}^{-2}\right)$, and the surface areas of these regions in a unit size of the greenhouse $\left(\mathrm{A}_{\text {cover }}\right)\left(\mathrm{m}^{2}\right)$ [1]. Based on this equation, total net global radiation gains $\left(Q_{\text {sum net }}\right)$ of the reference and model greenhouses were calculated with the help of Eqs. (25) - (26).

$$
Q_{\text {sum net }}=\sum T_{i} \cdot Q_{\text {incoming }(i)} \cdot A_{\text {cover }(i)}
$$


The percentage increase in the transmittance of light secured with the model greenhouse was found by comparing the amounts of light passing through a unit of horizontal length in the reference and model greenhouses, and the percentage increase in the total amounts of light transmittance was found by comparing the total amounts of light transmittance predicted in the six-month period.

\section{Findings and Discussion}

\subsection{Model Greenhouse Designs Developed for Antalya and Muğla Provinces}

Figure 5 shows cross-sections of model greenhouses developed for Antalya and Muğla provinces. Model greenhouses developed for Antalya and Muğla provinces had respectively side wall heights of $288 \mathrm{~cm}$ and $292 \mathrm{~cm}$, middle block roof heights of $74 \mathrm{~cm}$, and roof ridge heights of $362 \mathrm{~cm}$ and $366 \mathrm{~cm}$. Block and total widths of the model greenhouses in a south to north direction were calculated respectively as follows: for Antalya conditions, $392 \mathrm{~cm}$ and $230 \mathrm{~cm}$ with a total of $1103 \mathrm{~cm}$, and for Muğla conditions, $392 \mathrm{~cm}$ and $231 \mathrm{~cm}$, with a total of $1102 \mathrm{~cm}$ (see Figure 5).

Table 3 gives values for the geometry of the model greenhouse roof surfaces, made from rectilinear parts. The values of the total surface area $(\Sigma A)$ of a unit horizontal length in the south-facing fronts of model greenhouses for Antalya and Muğla were calculated as 7.85 and $7.86 \mathrm{~m}^{2}$ respectively (see Table 3 ).
The cross-section measurements calculated were taken into account when determining the mean daily amounts of energy entering these greenhouses.

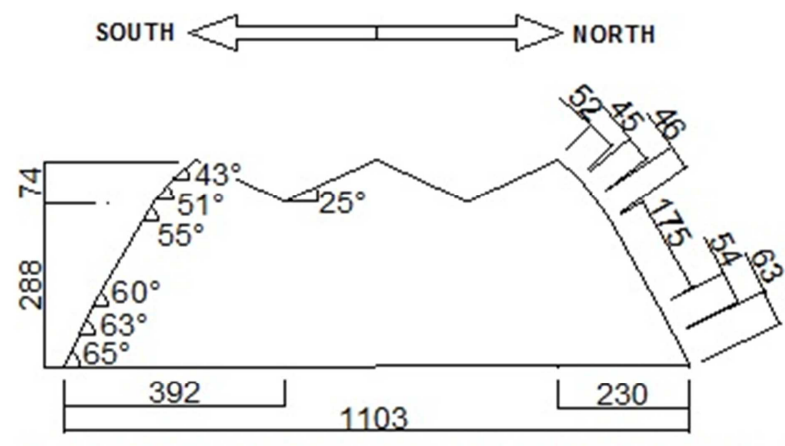

DEVELOPE D MODEL GREE NHOU SE FOR ANTALYA PROVIENCE

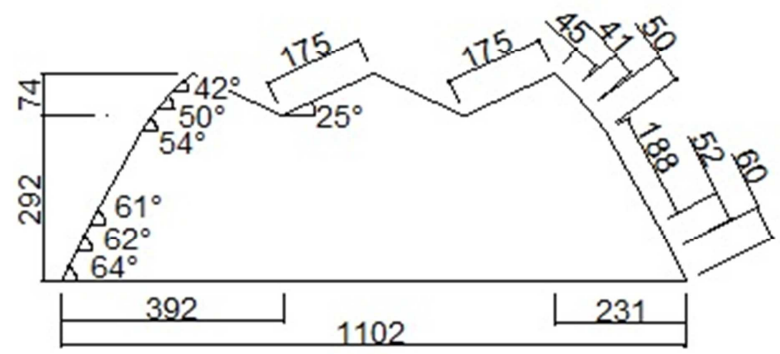

DEVELOPE D MODEL GREE NHOU SE FOR MUĞLA PROVIENCE

Figure 5. Cross-sections of model greenhouses developed for Antalya and Muğla provinces.

Table 3. Surface geometry of model greenhouses developed for Antalya and Muğla provinces.

\begin{tabular}{|c|c|c|c|c|c|c|}
\hline \multirow{2}{*}{$\begin{array}{l}\text { Model Green- } \\
\text { house Surface } \\
\text { No }\end{array}$} & \multicolumn{3}{|c|}{ For Antalya province } & \multicolumn{3}{|c|}{ For Muğla province } \\
\hline & Slope $\left(^{0}\right)$ & Lengths (cm) & $\begin{array}{l}\text { Surface area for } 1 \mathrm{~m} \text { horizontal } \\
\text { length }\left(\mathrm{m}^{2}\right)\end{array}$ & Slope $\left(^{\circ}\right)$ & Lengths (cm) & $\begin{array}{l}\text { Surface area for } 1 \mathrm{~m} \text { horizontal } \\
\text { length }\left(\mathrm{m}^{2}\right)\end{array}$ \\
\hline $\mathrm{a}$ & 65 & 63 & 1.75 & 64 & 60 & 1.75 \\
\hline $\mathrm{b}$ & 63 & 54 & 1.75 & 62 & 52 & 1.75 \\
\hline $\mathrm{c}$ & 60 & 175 & 0.63 & 61 & 188 & 0.60 \\
\hline d & 55 & 46 & 0.54 & 54 & 50 & 0.52 \\
\hline e & 51 & 45 & 1.75 & 50 & 41 & 1.88 \\
\hline f & 43 & 52 & 0.46 & 42 & 45 & 0.50 \\
\hline$g^{*}$ & 25 & 175 & 0.45 & 25 & 175 & 0.41 \\
\hline$h^{*}$ & 25 & 175 & 0.52 & 25 & 175 & 0.45 \\
\hline$\Sigma \mathrm{A}$ & & & 7.85 & $\Sigma \mathrm{A}$ & & 7.86 \\
\hline
\end{tabular}

*) Middle block roof construction in the model greenhouses was the same as in the reference greenhouse.

\subsection{Mean Daily Amounts of Solar Energy Passing Through a Unit Area of the South-Facing Surfaces of the Model and Reference Greenhouses}

A comparison of the mean amounts of solar energy passing through unit areas of the south-facing surfaces of the model and reference greenhouses ( $Q_{\text {incoming }}$ ) is given in Table 4 for the conditions of Antalya province and in Table 5 for the conditions of Muğla province.

Comparing the amounts of light transmittance, it was seen that the model greenhouses provided a greater amount of light transmittance each month than the reference greenhouses. It was found that particularly in December and January, the proportional difference was greater (12.10 and $12.71 \mathrm{Mjm}^{-2} \mathrm{day}^{-1}$ for Antalya, and 15.70 and $10.82 \mathrm{Mjm}^{-2} \mathrm{day}^{-1}$ for Muğla), while in the months at the beginning and end of the winter, the difference was less (3.44 and $4.98 \mathrm{Mjm}^{-2} \mathrm{day}^{-1}$ for Antalya, and 4.03 and $5.64 \mathrm{Mjm}^{-2} \mathrm{day}^{-1}$ for Muğla) (see Tables 4 and 5). 
Table 4. Comparison of the mean daily amounts of energy passing through a unit area of the south-facing surface of the model and reference greenhouses for Antalya province conditions.

\begin{tabular}{|c|c|c|c|c|c|c|c|c|}
\hline & \multicolumn{2}{|c|}{ Greenhouse surfaces } & \multicolumn{6}{|c|}{$\begin{array}{l}\text { Mean daily amounts of energy passing through a unit area of the greenhouse surfaces, } \\
\text { Q }_{\text {incoming }}\left(\mathrm{Mjm}^{-2} \mathrm{day}^{-1}\right)\end{array}$} \\
\hline & No & Slope $\left({ }^{\circ}\right)$ & Oct & Nov & Dec & Jan & Feb & March \\
\hline \multirow{9}{*}{$\begin{array}{l}\text { Model } \\
\text { Greenhouse }\end{array}$} & $\mathrm{a}$ & 65 & 8.60 & 7.60 & 2.15 & 6.43 & 7.48 & 7.01 \\
\hline & $\mathrm{b}$ & 63 & 8.79 & 7.64 & 2.19 & 6.59 & 7.64 & 7.16 \\
\hline & $\mathrm{c}$ & 60 & 9.01 & 7.68 & 2.22 & 6.52 & 7.6 & 7.25 \\
\hline & d & 55 & 9.32 & 7.42 & 2.01 & 6.25 & 7.65 & 8.23 \\
\hline & $\mathrm{e}$ & 51 & 9.42 & 7.23 & 1.98 & 6.27 & 7.86 & 8.34 \\
\hline & $\mathrm{f}$ & 43 & 8.88 & 6.54 & 1.63 & 5.57 & 7.21 & 8.62 \\
\hline & $\mathrm{g}$ & 25 & 6.53 & 4.94 & 0.98 & 4.37 & 5.69 & 7.21 \\
\hline & $\mathrm{h}$ & 25 & 6.53 & 4.94 & 0.98 & 4.37 & 5.69 & 7.21 \\
\hline & \multicolumn{2}{|c|}{$\begin{array}{l}\text { Total daily amounts of energy passing } \\
\text { through a unit of horizontal length of } \\
\text { greenhouse surface } \\
\text { Qsum net }\left(\mathrm{Mjm}^{-2} \text { day }^{-1}\right)\end{array}$} & 8.48 & 3.88 & 4.62 & 5.57 & 6.15 & 57.25 \\
\hline \multirow{5}{*}{$\begin{array}{l}\text { Reference } \\
\text { Greenhouse }\end{array}$} & 1 & 90 & 8.50 & 6.22 & 1.61 & 5.19 & 6.76 & 6.98 \\
\hline & 2 & 25 & 8.40 & 6.13 & 1.58 & 5.13 & 6.63 & 6.93 \\
\hline & 3 & 25 & 8.40 & 6.13 & 1.58 & 5.13 & 6.63 & 6.93 \\
\hline & 4 & 25 & 8.40 & 6.13 & 1.58 & 5.13 & 6.63 & 6.93 \\
\hline & $\begin{array}{l}\text { Tota } \\
\text { thro } \\
\text { gree } \\
\text { Qsu }\end{array}$ & $\begin{array}{l}\text { through a unit of horizontal length of } \\
\text { greenhouse surface }\end{array}$ & 66.20 & 48.35 & 12.48 & 40.43 & 52.38 & 54.53 \\
\hline \multicolumn{3}{|c|}{ Monthly differences (\%) } & 3.44 & 1.42 & 17.10 & 12.72 & 7.19 & 4.98 \\
\hline \multicolumn{3}{|c|}{ Overall difference (\%) } & +7.86 & & & & & \\
\hline
\end{tabular}

Table 5. Comparison of the mean daily amounts of energy passing through a unit area of the south-facing surface of the model and reference greenhouses for Muğla province conditions.

\begin{tabular}{|c|c|c|c|c|c|c|c|c|}
\hline & \multicolumn{2}{|c|}{ Greenhouse surfaces } & \multicolumn{6}{|c|}{$\begin{array}{l}\text { Mean daily amounts of energy passing through a unit area of the greenhouse surfaces, } \\
\text { Qincoming }\left(\mathrm{Mjm}^{-2} \mathrm{day}^{-1}\right)\end{array}$} \\
\hline & No & Slope (o) & Oct & Nov & Dec & Jan & Feb & March \\
\hline \multirow{9}{*}{$\begin{array}{l}\text { Model } \\
\text { Greenhouse }\end{array}$} & $\mathrm{a}$ & 64 & 8.47 & 7.51 & 2.01 & 6.39 & 7.38 & 6.72 \\
\hline & $\mathrm{b}$ & 62 & 8.67 & 7.52 & 2.03 & 6.38 & 7.46 & 6.97 \\
\hline & $\mathrm{c}$ & 61 & 8.76 & 7.52 & 2.03 & 6.37 & 7.50 & 7.09 \\
\hline & $\mathrm{d}$ & 54 & 9.20 & 7.33 & 1.93 & 6.14 & 7.61 & 7.85 \\
\hline & $\mathrm{e}$ & 50 & 9.27 & 7.06 & 1.82 & 5.91 & 7.55 & 8.16 \\
\hline & $\mathrm{f}$ & 42 & 8.79 & 6.36 & 1.55 & 5.36 & 7.05 & 8.44 \\
\hline & $\mathrm{g}$ & 25 & 6.50 & 4.83 & 0.92 & 4.22 & 5.59 & 7.06 \\
\hline & $\mathrm{h}$ & 25 & 6.50 & 4.83 & 0.92 & 4.22 & 5.59 & 7.06 \\
\hline & \multicolumn{2}{|c|}{$\begin{array}{l}\text { Total daily amounts of energy passing } \\
\text { through a unit of horizontal length of } \\
\text { greenhouse surface } \\
\text { Qsum net }\left(\mathrm{Mjm}^{-2} \text { day }^{-1}\right)\end{array}$} & 67.04 & 54.04 & 13.77 & 44.89 & 55.47 & 55.40 \\
\hline \multirow{5}{*}{$\begin{array}{l}\text { Reference } \\
\text { Greenhouse }\end{array}$} & 1 & 90 & 8.27 & 6.33 & 1.53 & 5.28 & 6.68 & 6.70 \\
\hline & 2 & 25 & 8.18 & 6.30 & 1.51 & 5.10 & 6.57 & 6.67 \\
\hline & 3 & 25 & 8.18 & 6.30 & 1.51 & 5.10 & 6.57 & 6.67 \\
\hline & 4 & & 8.18 & 6.30 & 1.51 & 5.10 & 6.57 & 6.67 \\
\hline & \multicolumn{2}{|c|}{$\begin{array}{l}\text { Total daily amounts of energy passing } \\
\text { through a unit of horizontal length of } \\
\text { greenhouse surface } \\
\text { Qsum net }\left(\mathrm{Mjm}^{-2} \text { day }^{-1}\right)\end{array}$} & 64.45 & 49.53 & 11.91 & 40.50 & 51.86 & 52.44 \\
\hline \multicolumn{3}{|c|}{ Monthly differences (\%) } & 4.03 & 9.10 & 15.70 & 10.82 & 6.96 & 5.64 \\
\hline \multicolumn{3}{|c|}{ Overall difference (\%) } & +7.36 & & & & & \\
\hline
\end{tabular}

It was seen from the comparison that the model greenhouse designed for Antalya province gained $7.86 \%$ more total net global radiation than the reference greenhouse (see Table 4), while the model greenhouse designed for Muğla province gained $7.36 \%$ more total net global radiation than the reference greenhouse (see Table 5), that is they had much greater sunlight transmittance.

\section{Conclusion}

In periods when heating is necessary in greenhouses, bringing the highest possible amount of sunlight into the greenhouse means reducing heating expenses, which significantly increase production costs. Therefore, because of the reduction in the 
angle at which solar radiation strikes the surface of the Earth in winter months, it is necessary to increase the slope angles of the greenhouse surface and to ensure that solar radiation strikes the greenhouse surface perpendicularly.

As the angle which the sunlight arriving at the greenhouse surface makes with the normal of the surface increases, transmission coefficients decrease. In particular, before midday and in the following hours, a large angle between the light and the surface normal increases losses. In the model and reference greenhouses which were compared, the angles made with the surface normal were high in this time slice. In particular, a great reduction in the passage of light occurs after $60^{\circ}$, and with high incidence angles, the importance of the angle made with the normal increases. As can be seen from the nomogram of light transmittance coefficients (see Fig 3), for example, an angle of $50^{\circ}-60^{\circ}$ reduces the light transmittance coefficient by $7 \%, 60^{\circ}-70^{\circ}$ by $17 \%, 70^{\circ}-80^{\circ}$ by $27 \%$, and $80^{\circ}-90^{\circ}$ by $96 \%$. For this reason, the slope of the greenhouse surface is important in increasing the efficiency of light transmittance, especially in the hours before and after midday. Therefore, the south-facing surfaces of the model greenhouses for both Antalya and Muğla provinces (side walls and roof surfaces) were designed with six different slopes and lengths so as to increase light transmittance and thus total net global radiation gain.

The geometry of the model greenhouse developed for Antalya province secured a total of $7.86 \%$ higher light transmittance in the winter months than the reference greenhouse, while the one developed for Muğla province achieved $7.36 \%$, and in

months like January and February when the hours of sunshine and the intensity of the light are less, the increase in light transmittance obtained rose to $17.10 \%$. These results show that the side surface geometry of the model greenhouses can be applied. Also, because of the vaulted structure of the model greenhouse, it can be constructed at lower cost than the reference greenhouse, so that it has advantages such as covering wider area.

The geometry of both of the model greenhouses which were developed enable fixed surface greenhouses to derive more benefit from solar radiation. In the future, suitable construction and mechanical solutions will enable movable greenhouse surfaces which will meet the solar radiation perpendicularly, and this will greatly increase the percentage benefit derived from the sun's radiation.

\section{References}

[1] Akdur B., Design and simulation of insulated composite wall to heat air with solar energy, Ege University Engineering Faculty Department of Mechanical Engineering dissertation, 2012, 92 p.

[2] Ali S. A., Modeling of some solar radiation available at different orientations of greenhouses, Misr J. Agric. Eng., 2012, 29 (3): 1181-1196.
[3] Bayraktar S., http://ekonomi.haber7.com/ekonomi/haber/872837-turkiyetarimsal-alanda-14-sirada, October 2013

[4] Beckman W. A. and Duffie John A., Solar engineering of thermal processes, ( $2^{\text {nd }}$ ed.), $1991,910 \mathrm{p}$.

[5] Cakır U, Sahin E. Using solar greenhouses in cold climates and evaluating optimum type according to sizing, position and location: a case study. Comput Electron Agric. 2015; 117: 245- 257.

[6] Cooper P. I., 1969. The absorption of solar radiation in solar stills. Solar Energy, 12 (3): 333-346

[7] Von Elsner, B., Briassoulis D., Waaijenberg D., Mistriotis A., Von Zabeltitz C. Gratraud, J., \& Suay-Cortes R., Review of structural and functional characteristics of greenhouses in European Union countries: Part I, design requirements, Journal of Agricultural Engineering Research, 2000, 75 (1), 116.

[8] Emekli N. Y. and Büyüktaş K., Mechanical properties of greenhouse covering materials, Derim. 2006, 23 (2): 24-35.

[9] Hemming, S., Mohammadkhani, V., Kempkes, F., Peters, A., Lieffrig, V., Harada, K. ... \& Louter, C. (2018). Feasibility study thin glasses for greenhouse roof designs (No. WPR732). Wageningen University \& Research, BU Greenhouse Horticulture.

[10] Hocagil M. M., Demirtaş B. and Keleş D., Determination of technical characteristics of and technology use in greenhouses in Mersin province, Alata Horticultural Research Institute, 2005, 49 p.

[11] Kaynaklı Ö., Özdemir. S. ve Karamangil. M. İ., Determination of optimum thermal insulation thickness considering solar radiation and wall orientation, Journal of the Faculty of Engineering and Architecture of Gazi University, 2012, 27 (2): $367-374$.

[12] Kincay O., Lecture notes. http://www.yildiz.edu.tr/ okincay dersnotu/gun-iki.pdf, 2013a

[13] Kincay O., Lecture notes http://www.yildiz.edu.tr/ okincay/dersnotu/gun-uc.pdf, 2013b

[14] Olgun, M.,. Farm Structures. Ankara University Faculty of Agriculture, 1577, 2011, 445 p.

[15] Saltuk B., A research on the structural analysis and development of plastic greenhouses in Mersin province and its districts, Çukurova University Faculty of Agriculture Department of Farm Structures and Irrigation, dissertation, 2005,79 p.

[16] TUIK. http://www.tuik.gov.tr/PreTablo.do?alt_id=1001, 2018.

[17] Von Zabeltiz, C., Energy-Efficent Greenhouse Designs for Mediterranean Countries. Plasticulture, 1992, 96: 6-16.

[18] Waaijenberg D., State-of-the-art in dutch greenhouse constructions, IMAG-DLO, Wageningen, The Netherlands, 1992, $112 \mathrm{p}$.

[19] Yağcioğlu A., Demir V. and Günhan T., Determination of the main greenhouse shapes and sizes to ensure maximum penetration of photosynthetically active radiation in various regions of Turkey, Ege University Research Funda, 1998, Project No: 96-ZRF-045. 
[20] Yağcioğlu A. Demir V. and Günhan T., A Computation Procedure for Estimating the Effective Transmitted Sun Radiation into the Greenhouse - Part I, Ege University Journal of The Faculty of Agriculture, 2004, 41 (2): 143-154

[21] Yilmaz T. Bulut H. ve Özgören. M., Total solar radiation through glass as heat gain, Çukurova Unıversity Journal of The Faculty of Engineering and Architecture, 1996, 11 (2): 133-146.
[22] Yüksel. A. N. Greenhouse construction technique, Hasat Publication, İstanbul, 2000, 335 p. 